\section{Slađana D. Mandić}

Studentkinja doktorskih studija

Univerzitet u Novom Sadu

Filozofski fakultet

smandic2018@gmail.com
UDK 811.163.41'371.72:811.111'371.72

DOI: 10.19090/zjik.2019.11-32

originalni naučni rad

\title{
SLIKOVNE SHEME U POSLOVICAMA KOJE SADRŽE SOMATIZME U ENGLESKOM I SRPSKOM JEZIKU: IZ KOGNITIVNOLINGVISTIČKE PERSPEKTIVE
}

SAŽETAK: Predmet istraživanja u ovom radu su slikovne sheme SADRŽATELJ, SILA, RAVNOTEŽA, CENTAR-PERIFERIJA, GORE-DOLE, i PREDMET (Johnson 1987: 126) u poslovicama koje sadrže somatizme u engleskom i srpskom jeziku poput, Place one's head in the lion's mouth / Staviti glavu na kocku. U istraživanju je korišćen korpus sačinjen od 30 poslovica engleskog i istog broja poslovica srpskog jezika. Cilj istraživanja jeste da se definišu metaforički pojmovni obrasci kojima je motivisana upotreba somatizama u posmatranim poslovicama, kao i da se predstave slikovne sheme kroz princip utelovljenja kao univerzalne kategorije. Kognitivnolingvističkom analizom pojmovnih obrazaca stiče se uvid u stepen sličnosti načina na koji govornici engleskog i srpskog jezika konceptualizuju apstraktne pojmove polazeći od delova ljudskog tela kao izvornih domena.

Ključne reči: poslovice, somatizmi, kognitivna lingvistika, slikovne sheme, engleski jezik, srpski jezik

\section{UVODNA RAZMATRANJA}

Svojom strukturom i značenjem poslovice su oduvek bile predmet interesovanja proučavalaca jezika. One predstavljaju značajna obeležja jednog naroda jer su spoj kulturoloških i tradicionalnih motiva. Skok (1971) navodi da poslovice ,predstavljaju individualno stvaralaštvo, inventivno formulisan zaključak iz životnog iskustva, prihvaćen u tradiciji. U jeziku one funkcionišu kao sažete, zaveštajne formulacije iskustva, jezgrovito izrečeno opažanje najčešće s poučnim smislom". Poslovice su uglavnom izražene $\mathrm{u}$ obliku rečenice ( $A$ bird in the hand is worth two in the bush, BOLJE VRABAC U RUCI NEGO GOLUB NA GRANI) i duboko su ukorenjene $\mathrm{u}$ jezik i narodno predanje. Poslovice obiluju prenesenim značenjem te se ono smatra polaznom osnovom za ovo istraživanje. Način na koji pripadnici različitih kultura prihvataju i tumače preneseno značenje 
oduvek je bio prijemčiv za razna istraživanja u lingvističkom svetu. U teoriji razlikujemo doslovno i preneseno značenje. Doslovno značenje se „smatra osnovnim za određenu leksemu“ (Prćić 2008: 31), dok je preneseno ono „koje je proisteklo iz doslovnog, putem metaforičkog ili metonimijskog prenosa“"(Ibid.). Navedeni način tumačenja prenesenog značenja predstavlja teorijski okvir ovog rada unutar kog će se porediti proširena značenja leksema kojima se označavaju somatizmi u engleskom jeziku kao i proširena značenja njihovih ekvivalenata u srpskom jeziku. Uzevši u obzir, na primer, doslovnu interpretaciju rečenice take one`s life in one`s hands 'uzeti život u svoje ruke' dolazimo do zaključka da je život predmet koji se može uzeti u ruke i nositi sa sobom. S druge strane, metaforička interpretacija rečenice znači da je 'pojedinac odlučan u nameri da ima potpunu kontrolu nad sopstvenim životom'. Prelazak doslovnog u preneseno značenje u radu biće objašnjen postulatima kognitivne lingvistike i semantike.

Kognitivna lingvistika kao interdisciplinarna grana lingvistike predstavlja istovremeno spoj psiholoških i lingvističkih znanja i istraživanja. Ona opisuje interakciju jezika i kognicije, uticaj naših misli na oblikovanje jezika, kao i evoluiranje jezika paralelno sa promenom zajedničkog mentalnog sklopa kroz vreme. Kognitivna lingvistika povezuje sistematičnost prikazanu u jeziku direktno sa načinom na koji je um organizovan, a naročito sa pojmovnom strukturom i organizacijom (Evans \& Green 2006: 15-16). Kao grana kognitivne lingvistike, kognitivna semantika bavi se fenomenom kategorizacije, teorijom prototipa i polisemijom. Takođe, istražuje različite vrste preslikavanja poput metaforičkog i metonimijskog. Kognitivna semantika stoji nasuprot objektivističkoj semantici, i smatra da se jezik ,ne odnosi samo na objektivnu stvarnost, nego na koncepte: konvencionalna značenja koja se odnose na reči i druge lingvističke jedinice, smatraju se usko povezanim sa mislima i idejama. Shodno tome, osnovno stanovište kognitivne semantike tiče se prirode odnosa između pojmovne strukture i ljudske interakcije sa spoljašnjim svetom senzornog iskustva“" (Ibid. 172). Kognitivna semantika koristi jezik kao ključno metodološko sredstvo za otkrivanje pojmovne organizacije i strukture (Ibid. 153). Istraživanje kognitivne semantike je istraživanje pojmovnog sadržaja i njegove organizacije u jeziku (Talmy 2000: 4). 
Veliku ulogu u tome kako konceptualizujemo svet oko sebe igra i kultura jer određene pojmove stvaramo na osnovu kulturnih obrazaca prisutnih u našem okruženju. Značaj ljudskog iskustva, centralna uloga ljudskog tela i kognitivne strukture, i organizacija koje su svojstvene samo ljudima imaju velik uticaj na prirodu iskustva (Evans \& Green 2006: 44). Ideja da se iskustvo zasniva na telesnom doživljaju implicira da ljudska vrsta ima specifičan način viđenja stvarnosti zbog jedinstvene prirode ljudskog tela, tj. strukturisanje stvarnosti posredovano je u velikoj meri prirodom ljudskog tela (Ibid. 45). Kako bi objasnili složenost ljudskog pojmovnog sistema, Lejkof i Džonson navode da je ,ovakva složenost, u velikoj meri, posledica tesne veze različitih koncepata koje su ljudi sposobni da formiraju i prirode naših fizičkih tela“ (Lakoff \& Johnson 1980). Za razumevanje složenosti ljudskog pojmovnog sistema značajan je pojam slikovna shema (engl. image schema), za koju Džonson navodi da je „dinamični obrazac čulne interakcije i motornih aktivnosti koje se stalno ponavljaju i koje daju koherenciju i strukturu ljudskom iskustvu“ (Johnson 1987: xiv). Ove strukture same po sebi imaju smisao ,jer ih neposredno i učestalo doživljavamo zahvaljujući prirodi tela i načinu funkcionisanja u svom okruženju“ (Lakoff 1987: 268) te su, prema tome, univerzalne. Vidimo da na osnovu telesnog iskustva nastaju konkretni pojmovi, a oni potom služe za strukturiranje apstraktnijih pojmovnih domena (Evans \& Green 2006: 157-158). Polazeći od ovog stanovišta, ,utelovljenje se smatra direktno odgovornim za stvaranje koncepata“ (Ibid. 177-178).

Mandler (2004) dodaje da slikovne sheme prethode stvaranju koncepata jer ,proističu iz senzornih iskustava u ranim fazama ljudskog razvoja“" (prema Evans \& Green 2006: 180). Mark Džonson u knjizi The Body in the Mind (Johnson 1987), daje primer senzornog iskustva koje stvara slikovnu shemu GORE-DOLE, smatrajući je rezultatom naše interakcije sa spoljašnjim svetom, koja je po svom poreklu predpojmovna. Na primer, ,ako posmatramo osobu koja se kreće uspravno, možemo da uočimo vertikalnu osu koja se proteže od glave ka stopalima i silu gravitacije koja privlači predmete naniže. Svaki pokušaj da se nešto podigne sa tla, podrazumeva savijanje pojedinca prema tom predmetu i promenu položaja tela ka dole“ (Evans \& Green 2006: 178). Ovakvo telesno iskustvo prethodi stvaranju slikovne sheme GORE-DOLE. 
Iz gorenavedenog proističe da su predmet istraživanja slikovne sheme SADRŽATELJ, SILA, RAVNOTEŽA, CENTAR-PERIFERIJA, GORE-DOLE i PREDMET (Johnson 1987: 126), dok istraživanje ima za cilj da definiše metaforičke pojmovne obrasce kojima je motivisana upotreba naziva delova tela u posmatranim poslovicama, i da predstavi princip utelovljenja kao univerzalnu kategoriju u oba jezika. Dosadašnja istraživanja na sličnu temu prvenstveno se bave mehanizmima pojmovne metafore i metonimije (Prodanović-Stankić (2009), Radić-Bojanić \& Silaški (2012a,b), Silaški \& Radić-Bojanić (2014), Cvetanović (2017), Živadinović (2016)). U ovom istraživanju sprovodi se kognitivnolingvistička analiza i to, konkretno, slikovne sheme na kojima se baziraju idiomi kako bi se pokazale tendencije ka univerzalnosti ovakvih konstrukcija. Imajući u vidu činjenicu da engleski i srpski pripadaju različitim porodicama jezika, slikovne sheme prisutne u oba jezika proističu iz utelovljenog iskustva, koje je svojstveno svima. Značaj istraživanja ogleda se u detaljnom prikazu ovih shema svojstvenih svima, koje nesvesno usvajamo, prepoznajemo svojim čulima, kroz pokrete u prostoru ili dok rukujemo predmetima.

\section{TEORIJSKI OKVIR: POJMOVNA METAFORA I IDIOMI}

Tradicionalni pristup u nauci o jeziku koji jasno razgraničava dva domena, doslovni i metaforički, smatra da je metafora „po definiciji figura, dakle stoji nasuprot nekom doslovnom izrazu na koji se može 'prevesti' (u odnosu na koji i stiče status figure), privlači pažnju kao neobičan izraz i svojom naročitom slikovitošću izaziva emotivnu reakciju, čime stiče status jezičkog "ukrasa"' (Klikovac 2004: 83). Naime, pitanje metafore datira još iz vremena Aristotela koji ga je pokrenuo u svojim delima Poetika i Retorika. Ono je svim teoretičarima i filozofima predstavljalo problem jer su se trudili da je vežu isključivo za domen književnosti, retorike i umetnosti. I lingvistima je bilo teško da je uklope u postojeće lingvističke teorije pa je često metafora prebacivana iz jedne grane lingvistike u drugu. Ono što je karakteristično za tadašnje tumačenje običnog, svakodnevnog jezika jeste činjenica da je doslovan, lišen bilo kakve metaforičnosti, i da treba da se prikaže što objektivnije i vernije. Kognitivnolingvistički pristup koji predstavlja preokret $u$ dotadašnjem poimanju lingvističke stvarnosti umnogome će doprineti rešavanju metaforičke zagonetke jer predstavlja spoj mišljenja i jezika. Veliki preokret na ovom polju donose Lejkof i 
Džonson u svojoj knjizi Metaphors We Live By (Lakoff \& Johnson 1980) koja pod terminom pojmovna metafora (engl. conceptual metaphor) podrazumeva deo našeg kognitivnog sistema koji se naposletku realizuje u jeziku. Kod (...) metafore, preneseno značenje izvodi se na osnovu sličnosti, stvarne ili pretpostavljene, između dva različita i nepovezana entiteta, $u$ pogledu oblika, pozicije, funkcije, namene, osobine, ponašanja, delovanja, sposobnosti itd. (Prćić 2008: 31-32). Pojmovna metafora je kognitivni mehanizam kod koga se jedan iskustveni domen (izvorni domen / engl. source domain) delimično projektuje na neki drugi iskustveni domen (ciljni domen / engl. target domain) (Lakoff \& Johnson 1980: 5). Izvorni domeni najčešće su jasno definisani i konkretni pojmovi (ljudsko telo, životinje, zgrade, itd.) dok su ciljni domeni obično apstraktni pojmovi (emocije, želje, vreme i sl.) (Kövecses 2002: 15). Izvorni i ciljni koncepti ne nastaju u izolaciji, već su zasnovani na 'kognitivnim' i 'kulturnim modelima'. Ono što se prenosi metaforom nisu samo svojstva kao sastavni delovi pojedinačnih koncepata, već struktura, unutrašnje veze ili logika celokupnog kognitivnog modela (Ungerer \& Schmid 2006: 118).

Naš pojmovni sistem, koji nam omogućava da mislimo i delujemo, zasnovan je na metafori. Koncepti koji upravljaju našim mislima nisu samo stvar intelekta. Oni oblikuju sve što opažamo, naš život i odnose sa drugim ljudima. Stoga, naš pojmovni sistem ima ključnu ulogu u definisanju naših svakodnevnih aktivnosti (...) što se jasno očituje u jeziku. Pošto se komunikacija bazira na istom pojmovnom sistemu koji koristimo u razmišljanju i delovanju, jezik je jasan pokazatelj strukture tog sistema (Lakoff \& Johnson 1980: 4).

Odnos između uma i jezičke strukture ilustrovaćemo pojmovnom metaforom RASPRAVA JE RAT. Ova metafora se u jeziku izražava raznim metaforičkim izrazima: Vaše tvrdnje su neodbranjive. Napao je svaku slabu tačku mog argumenta. Njegova kritika pogađa pravo u metu. Uništio sam njegov argument" (Ibid. 5). Iz navedenog zaključujemo da nije reč o fizičkom obračunu nego o verbalnom, u kojem su takođe prisutne aktivnosti poput napada, protivnapada, odbrane i sl. Koncept RASPRAVE delimično se formira, razume, izvodi i o njemu se govori kao o RATU. Koncept se metaforčki strukturira, aktivnost se metaforički strukturira, i naposletku, i sam jezik (Ibid. 6). U metafori VREME JE NOVAC, VREME se konceptualizuje pomoću materijalne opipljive stvari, NOVCA, koji je 
predmet trošenja. Samim tim se i vremenu pripisuje osobina dragocenosti, te se svako traćenje vremena poistovećuje sa traćenjem novca, što je očito u metaforičkim izrazima: Gubim vreme s tobom. Nemam vremena na bacanje. Izgubio sam mnogo vremena kad sam se razboleo (Ibid. 8).

Drugi kognitivni mehanizam, pored metafore, jeste pojmovna metonimija koja predstavlja ,razumevanje jednog iskustvenog domena pomoću drugog unutar zajedničkog iskustvenog domena" (Barcelona 2002: 148), te se smatra „fenomenom unutrašnjosti jednog domena” (Deignan 2005: 73). Naime, dok se pomoću metafore jedna stvar poima i shvata uz pomoć neke druge, metonimija nam pomaže da istaknemo jedan entitet iz date sheme pomoću nekog drugog entiteta iz iste sheme i ona uvek izražava odnos povezanosti po blizini (Ungerer \& Schmid 1996: 57). Kod (...) pojmovne metonimije, preneseno značenje izvodi se na osnovu bliskosti dvaju različitih ali međusobno prostorno, vremenski ili drukčije povezanih entiteta, unutar jednog istog domena (Prćić 2008: 32). Na primer, u rečenici Kupio sam Pikasa (Barcelona 2002: 150), Pikaso predstavlja umetničko delo koje je naslikao čuveni slikar, što je jedan od mehanizama metonimijskog preslikavanja, PROIZVOĐAČ ZA PROIZVOD. Pored ovog mehanizma, postoje i drugi poput DEO ZA CELINU, DEO ZA DEO, SADRŽAJ ZA SADRŽATELJA i sl. Ovde je neophodno napomenuti da metonimija nije predmet ovog rada ali će se neminovno pojavljivati.

\subsection{Kognitivnolingvistički pristup poslovicama}

Poslovice su vrsta idioma a ,idiomom se naziva redovan, a ponekad i sistematski spoj najmanje dve lekseme, a često više njih, kako semantičkih tako i funkcijskih, po pravilu unutar određene sintagme ili rečenice; npr. (as) cunning as a fox, LUKAV KAO LISICA" Prćić (2008: 158). Zaključujemo da „ovi spojevi predstavljaju više ili manje kompaktnu celinu - sa stanovišta forme, funkcije, sadržine i upotrebe (...)“(Ibid).

Kao vrsta idioma, tradicionalne izreke (poslovice) prikazane u radu „na kratak, jezgrovit, a povremeno i duhovit način, izražavaju neku mudru misao, istinu ili verovanje, zasnovano na iskustvu ili posmatranju. (npr. The early bird catches the worm, KO RANO RANI DVE SREĆE GRABI)“ (Ibid). Glavno svojstvo poslovica, kao vrste idioma, jeste idiomatizovanost na sadržinskom i/ili formalnom planu. Sadržinska idiomatizovanost se odnosi 
na značenje koje idiom kao celina dobija gubljenjem nekih obeležja leksema koje ulaze u njegov sastav i dodavanjem novih obeležja celini (ProdanovićStankić 2008: 31).

Sadržinska idiomatizovanost je skalarna osobina i doprinosi tome da su neki idiomi prozirni, odnosno njihovo značenje je skup značenja leksema koje ulaze u njegov sastav, ili neprozirni, te svoje značenje dobijaju metaforičkim/metonimijskim prenosom. Kada je u pitanju forma, poslovice pokazuju nemoguću zamenljivost, relativno visoku postojanost, sa slabom podložnošću modifikacijama i transformacijama (Prćić 2008: 165).

Kod nekih idioma, štaviše, prenos značenja sinhrono je gotovo neprepoznatljiv, pa se može razaznati jedino pribegavanjem etimologiji (...) kick the bucket, OTEGNUTI PAPKE (Ibid. 159). Preneseno značenje kao jedno od najvažnijih obeležja poslovica prikazano je mehanizmom pojmovne metafore. Na primer, poslovica Staviti glavu na kocku, „sadrži metaforu GLAVA JE DRAGOCEN PREDMET“ (Radić-Bojanić, Silaški 2012: 34) kojom se gubitak glave koja doslovno označava vitalni deo ljudskog tela, metaforičkim prenosom poistovećuje sa gubitkom života, ili visoko rizičnim postupcima. Poslovice imaju za cilj da objasne, usmere ili osude ponašanje ljudi ili određene situacije. Naime, u pokušaju da objasni određene apstraktne i složene pojave, pojedinac poseže za poznatim i jednostavnim slikama. Poslovice obiluju slikovnim shemama. Džonson navodi da je ,slikovna shema dinamični obrazac čulne interakcije i motornih aktivnosti koje se stalno ponavljaju i koje daju koherenciju i strukturu ljudskom iskustvu“ (Johnson 1987: xiv). To su predpojmovne strukture koje se usvajaju i pre usvajanja jezika, tačnije, ,znanje koje imamo o nekim fizičkim iskustvima ili pojavama zajedničko govornicima jednog jezika i predstavlja deo te culture“ (Prodanović-Stankić 2008: 25). Metafora koja je najčešće u njihovoj osnovi je GENERIČKO JE SPECIFIČNO (Lakoff \& Turner 1989: 172). Ova metafora nam „omogućava da poimamo različite situacije pomoću jedne specifične situacije“ (Prodanović-Stankić 2008: 26) i razumemo svaku poslovicu, jer specifičnu shemu/sliku projektujemo na bezbroj opštih situacija, koje moraju da sadrže izvornu specifičnu slikovnu shemu. Na primer, u poslovici Vrana vrani oči ne vadi, vrana se uvek odnosi na ljudsko biće, i na činjenicu da pripadnici iste 
interesne grupe/organizacije nikada ne protivreče jedni drugima, već rade $\mathrm{u}$ zajedničkom interesu svih pripadnika grupe/organizacije.

U kognitivnoj lingvistici, slikovna shema se shvata kao

...utelovljeno prepojmovno iskustvo koje motiviše preslikavanja pojmovne metafore, i igra važnu ulogu u našem poimanju stvarnosti. Kao modeli senzorno-motornog iskustva, slikovne sheme igraju ključnu ulogu u nastanku značenja i našoj sposobnosti da konceptualizujemo i zaključujemo na apstraktan način što je bazirano na našem telesnom iskustvu sa okruženjem (Johnson 2005: $15)$.

Slikovne sheme organizuju naše znanje i predstavljaju sastavni deo kognitivnih modela pomoću kojih usvajamo nova iskustva ili razmišljamo o njima. Stvaramo ih pomoću neposrednog iskustva ili uz pomoć kulturnih obrazaca iz svog okruženja (Lakoff i Turner 1989: 65). Sheme, tj. naše znanje, postaju opštepoznate i prihvaćene a pojmovne metafore stvorene na osnovu tog znanja postaju duboko ukorenjene u jezik govornika. Tako se neka situacija može metaforički objasniti i shvatiti pomoću specifične i poznate sheme (Prodanović-Stankić 2008: 32). Na primer, u metafori VREME JE LINEARNO KRETANJE pojam vremena se razume pomoću pojmova kretanja i prostora. Iz toga proizlaze sledeća „metaforička preslikavanja: VREME JE POKRETNI OBJEKAT; PROTOK VREMENA JE KRETANJE; BUDUĆNOST JE ISPRED POSMATRAČA A PROŠLOST IZA itd." (Prodanović-Stankić 2008: 25). VREME JE POKRETNI OBJEKAT pronalazimo u primerima Prolazi leto. Uskoro stiže Božić, u kojima se vremenu pripisuju osobine živih bića koja se kreću u prostoru. Vreme se može predstaviti i na horizontalnoj osi gde se budućnost nalazi ispred posmatrača i osobe koja se kreće, dok je prošlost iza i osoba se udaljava od nje krećući se napred prema budućnosti. Linearnim kretanjem osobe kroz prostor i vreme, i samo vreme se pomera pa tako razlikujemo delove dana (jutro, podne, veče, noć), dane u nedelji (ponedeljak, utorak itd.), mesece (januar, februar itd.), godine i sl. U poslovici Daleko od očiju, daleko i od srca, pored očigledne udaljenosti dve osobe u prostoru, prisutna je i znatna vremenska distanca koja utiče na slabljenje jačine emocija. Možemo zaključiti da se vreme neumitno kreće kretanjem osobe i udaljavanjem od epicentra emocija te njihova jačina, samim tim, biva sve slabija i slabija. 
Druga metafora prisutna u poslovicama je VELIKI LANAC POSTOJANJA (engl. THE GREAT CHAIN OF BEING) (Lakoff \& Turner 1989), kojim je uređena hijerarhija svega postojećeg u univerzumu. To je vertikalna skala bića (ljudi, životinja, biljaka) i predmeta na kojoj se „viša“ bića i svojstva nalaze iznad „nižih bića i svojstava“ (Ibid. 166). Bića na višem nivou su složenija, imaju neka svojstva koja ona na nižem nemaju te tako dominiraju njima. Smisao ove metafore ogleda se u tome da se pojmovi na jednom nivou hijerarhije predstavljaju putem pojmova iz drugog nivoa hijerarhije. Na primer, u poslovici Zabiti glavu u pesak, ponašanje tipično ptici noju kada se nađe u nevolji preslikava se na ponašanje ljudi u kriznim situacijama kada se osećaju nemoćni i uplašeni. Čovek koji je na višem nivou hijerarhije oponaša ponašanje životinje koja je na nižem nivou velikog lanca postojanja. Naime, bića višeg reda karakteriše ponašanje koje je teže shvatiti i objasniti (Prodanović-Stankić 2008: 27). U poslovicama se ovakvo ponašanje lakše razumeva pomoću bića nižeg reda i njihovog karakterističnog instinktivnog ponašanja koje čini predpojmovno iskustvo.

\section{KORPUS I METODOLOGIJA ISTRAŽIVANJA}

Korpus čine poslovice sa leksemama kojima se označavaju somatizmi na engleskom jeziku i njihovi srpski prevodni ekvivalenti. Analiza obuhvata 30 poslovica sa delovima tela poput head, eyes, ears, tongue, hand, finger, heart, belly, foot, na engleskom jeziku i 30 prevodnih ekvivalenata u srpskom jeziku kao što su glava, oči, uši, jezik, ruka, prst, srce, stomak, stopalo, što ukupno čini 60 poslovica u oba jezika. Analiza polazi od primera na engleskom jeziku za koje pronalazi adekvatne prevodne ekvivalente u srpskom jeziku. Posmatra se prisustvo istih somatizama u oba jezika, značenje celokupnog izraza, kao i slikovne sheme i njihova univerzalnost na oba govorna područja, engleskom i srpskom.

Kognitivnolingvistička analiza predstavljena je kroz slikovne sheme SADRŽATELJ, SILA, RAVNOTEŽA, CENTAR-PERIFERIJA, GOREDOLE i PREDMET, unutar kojih se definišu metaforički pojmovni obrasci, kojima je motivisana upotreba naziva delova tela u poslovicama u dva posmatrana jezika i koji leže u osnovi određenih nedoslovnih značenja. Utvrđena su dominantna prenesena značenja leksema koje imenuju spoljašnje delove ljudskog tela i dato je objašnjenje za uočene tendencije. Primeri su prikazani kroz pododeljke slikovnih shema kako bi se podrobnije 
objasnio koncept utelovljenja budući da slikovne sheme stvaramo neposrednom interakcijom sa okruženjem, stoga one na najbolji način objašnjavaju telesno predpojmovno iskustvo. Čovek preko delova svog tela opaža svet, dolazi u dodir sa istim, kreće se kroz njega ili biva sadržan u njemu.

Primeri na engleskom jeziku ekscerpirani su iz rečnika Collins COBUILD Dictionary of Idioms (1995), Dictionary of Selected Collocations (1997), Longman Collocation Dictionary and Thesaurus (2013) Longman Dictionary of English Idioms (1990), Macmillan Collocations Dictionary (2010), Oxford English Idioms (1988), The BBI Dictionary of English Word Combination (1997), The Penguin Dictionary of English Idioms (1986), dok su primeri na srpskom jeziku iz rečnika Englesko-srpski rečnik fraza $i$ idioma (1995), Srpsko-engleski rečnik idioma (1991), Srpsko-engleski rečnik idioma, izraza $i$ izreka (1992), kao i sa sajtova: http://www.idiomconnection.com, http://idioms.thefreedictionary.com.

\section{ANALIZA}

Rezultati analize obuhvataju prikaz slikovnih shema unutar kojih su date reprezentativne poslovice iz korpusa. Prvo se prikazuje slikovna shema SADRŽATELJ, potom, slikovna shema SILA, slikovna shema GORE-DOLE, zatim, slikovna shema RAVNOTEŽA posle koje sledi slikovna shema CENTAR-PERIFERIJA, i naposletku, slikovna shema PREDMET.

\subsection{Slikovna shema SADRŽATELJ}

Kako navodi Džonson, „slikovne sheme su od izuzetnog značaja jer nam omogućavaju da koristimo strukturu senzorno-motornih operacija kako bismo razumeli apstraktne koncepte i došli do određenih zaključaka o njima“ (Johnson 1987). Drugim rečima, ,ljudi mogu da shvate kada je nešto smešteno unutar nekog sadržatelja. Kada vide taj sadržatelj, čuju ili pročitaju predlog ' $u$ ', aktivira se slikovna shema SADRŽATELJA koja je ključna za razumevanje određene situacije“" (Johnson 2005: 22). Ako uporedimo primere poslovica sa delovima ljudskog tela u engleskom i srpskom jeziku, doći ćemo do sličnih zapažanja jer „naša svakodnevna telesna iskustva koja uključuju naše ruke stvaraju pojmovne sheme na osnovu kojih nastaju apstraktniji i složeniji koncepti“" (Yu 2009: 112). 
Poslovica, have somebody in the palm of one`s hand / imati nekog $u \check{s}$ aci, sadrži metaforu kontrole, UPRAVLJATI ZNAČI DRŽATI, gde je ruka/hand konceptualizovana poput SADRŽATELJA, tj. onog koji ima kontrolu nad nekim drugim.

Džonson tvrdi da je „naš susret sa sadržavanjem i ograničenošću jedno od najuticajnijih svojstava našeg telesnog iskustva“" (Johnson 1987: 21). „Tri strukturna elementa čine shemu SADRŽATELJA: „unutrašnjost“, „spoljašnjost“ i „okvir“ i organizacija ovih strukturnih elemenata daje smisao našem iskustvu“" (Johnson 1987: 61). U primeru be in good hands/ biti u dobrim rukama, prisutna je metafora ČOVEK JE SADRŽATELJ ZA DRUGOG ČOVEKA (Klikovac 2004: 298), gde jedna osoba predstavlja utočište i sigurnost za drugu koju je zadesila izvesna nevolja. Shema SADRŽATELJA prisutna je i u primeru get into someone's headl ući u nečiju glavu, i označava ulazak u ograničen prostor protivno nečijoj volji. Zapravo, „glava je konceptualizovana poput sadržatelja koji, slično bilo kom sadržatelju, može biti ispunjena određenim sadržajem“ (Radić-Bojanić, Silaški 2012: 35). Drugim rečima, ovi izrazi se „fokusiraju ili na popunjenosti ili praznini glave ili na dinamičnom procesu punjenja ili pražnjenja glave“ (Niemeier 2008: 363). Ovi procesi se uočavaju u poslovicama to drum/put/beat sth into sb's headl puniti nekome glavu 'nagovarati nekoga na nešto', ili, to knock sth out of sb's head/ izbiti nekome nešto iz glave, koji pokazuju stavljanje ili uklanjanje određenog sadržaja iz nečije glave, nekog sadržatelja, što se može predstaviti metaforom MENTALNI PROSTOR JE FIZIČKI PROSTOR (Klikovac 2004: 247).

\subsection{Slikovna shema SILA}

Čovek je biće koje je u stalnoj vezi sa univerzumom, kreće se kroz njega i tako stvara svoje utelovljeno iskustvo. „Zbog našeg stalnog telesnog dodira sa silama koje nas guraju i vuku, mi osećamo shematske strukture PRISILNOSTI, PRIVLAČENJA i BLOKADE POKRETA, kojima se može imenovati nekolicina pojava koje Talmi (Talmy 1983) naziva 'dinamikama sile"“ (prema Johnson 2005: 20). U poslovici bang/bash one's head against a brick wall razbijati glavu o nečemu, vidimo da se unutar sheme SILE, udara glavom o zid, koji je čvršći od glave, u cilju da se ona otvori kako bi se sadržaj unutrašnjosti oslobodio ili novi upio, tj. došlo do rešenja problema koji nekoga tišti. Beležimo prisustvo pojmovne metafore 
NANOŠENJE ŠTETE JE FIZIČKA POVREDA (MML), ${ }^{1}$ takođe zastupljena u poslovicama not harm a hair of sb's headl neće ti faliti ni dlaka s glave, kojom se garantuje nečija sigurnost i bezbednost. Takođe, uočavamo i prisustvo metonimije DEO ZA CELINU, gde dlaka stoji umesto glave, a samim tim i osobe kao celine.

\subsection{Slikovna shema GORE-DOLE}

Slikovna shema GORE-DOLE predstavlja orijentaciju i prostorne odnose. Glava kao pokretni deo ljudskog tela može da se pomera gore-dole, pa se prema njenom položaju konceptualizuju emocije. Povijena glava na dole označava negativne emocije poput tuge, stida, dok uzdignuta glava označava pozitivne emocije poput sreće, zanosa i sl. Prema položaju na kom su emocije konceptualizovane na vertikalnoj osi, generišu se odgovarajuće pojmovne metafore. U izrazima keep one's head down / gledati u zemlju prisutne su pojmovne metafore NEMOĆ/STID/TUGA JE DOLE (Klikovac 2004: 303, 305) koje pokazuju da je osoba nemoćna/postiđena/tužna prema osnovnoj metafori LOŠE JE DOLE. Suprotno ovom, izrazi hold one's head high/up/in the clouds / visoko uzdignute glave; sanjariti ukazuju na osećaj ponosa i sreće prikazanih metaforom SREĆA JE GORE.

\subsection{Slikovna shema RAVNOTEŽA}

Poput slikovne sheme GORE-DOLE, koja ukazuje na prostorne odnose, slikovna shema RAVNOTEŽA pokazuje kretanje delova tela $\mathrm{u}$ pravcu koji nije pravolinijski. Takvi pokreti kada je glava u pitanju „stvaraju kod pojedinca osećaj vrtoglavice, što metaforički predstavlja gubitak racionalnog mišljenja i sposobnosti da se jasno rasuđuje, što se vidi u izrazima“ (Radić-Bojanić, Silaški 2012: 33) make somebody's head spin / zavrteti nekome glavu. U ovim poslovicama prisutna je pojmovna metafora EMOCIONALNA STABILNOST JE RAVNOTEŽA (MML) kojom se jasno naglašava da svaki poremećaj ravnoteže dovodi do narušavanja emocionalne stabilnosti.

\footnotetext{
${ }^{1}$ Skraćenica za Master Metaphor List.
} 


\subsection{Slikovna shema CENTAR-PERIFERIJA}

Mi, ljudi, smo pokretna bića i krećemo se kroz prostor.

Zbog određenog utelovljenja, manifestujemo pokrete poput DESNO i LEVO, NAPRED i NAZAD, BLIZU i DALEKO, kroz horizont naših čulnih interakcija. Sam koncept HORIZONTA je poput slikovne sheme. Naša čula imaju određene tačke fokusa koje se utapaju u nebrojeno mnogo iskustava koja trenutno nisu u centru naše svesti. Stoga, potpuno je razumljivo da imamo slikovnu shemu CENTAR-PERIFERIJA (Johnson 2005: 20).

Poslovica a bird in the hand is worth two in the bush / bolje vrabac u ruci nego golub na grani sadrži metaforu BLIŽE JE BOLJE koja ukazuje na to da je bolje posedovati nešto manje vredno nego maštati o nečemu što je vrednije, daleko i neizvesno. Ruka je predstavljena u centru i metonimijskom shemom upućuje na osobu kao celinu. Takođe, možemo uočiti i slikovnu shemu SADRŽATELJA što se vidi u leksemi hand/ruka kojom se nešto drži, pa shodno tome i metaforu POSEDOVANJE JE DRŽANJE (MML). Takođe, poslovica far from eye, far from heart / daleko od očiju, daleko i od srca pokazuje uticaj prostorne udaljenosti na jačinu emocija. Jake emocije koje su u centru postaju slabije udaljavanjem od centra. Tačnije, ,preko domena vida objašnjava se apstraktniji domen ljudske kognicije" (Halas-Popović 2012: 282), i emotivnog stanja, što se odslikava u pojmovnoj metafori VOLETI ZNAČI VIDETI.

\subsection{Slikovna shema PREDMET}

„Kao što je i Svedek pokazao u svojim mnogobrojnim radovima $(2000,2002,2009,2011,2014)$, predmeti su ti koji su osnova naše fizičke stvarnosti, krajnji domen metaforizacije, i jedini elementi naše stvarnosti čulno opipljivi“ (Szwedek 2017: 5). Predmet je uokvirena masa čija se gustina prvenstveno utvrđuje dodirom (Grady 2005: 35). Polazeći od ovih tvrdnji, poslovica place one's head in the lion's mouth / staviti glavu na kocku, 'rizikovati život' „sadrži metaforu GLAVA JE DRAGOCEN PREDMET“ (Radić-Bojanić, Silaški 2012: 34) u kojoj je gubitak glave identičan gubitku života, i podrazumeva visoko rizičan i nepromišljen potez. Glava je u ovoj poslovici konceptualizovana poput dragocenog predmeta čijim gubitkom dolazi do neželjenih posledica. Uočavamo nekoliko razlika 
u pogledu forme. Što se tiče značenja poslovica, zaključujemo da je glava konceptualizovana poput dragocenog predmeta, što je jednako u oba jezika.

\section{DISKUSIJA}

Nakon detaljne analize navedenih primera uočavamo da je konceptualizacija delova ljudskog tela i u engleskom i u srpskom jeziku veoma slična. Pojmovne metafore, metonimije i slikovne sheme, zastupljene u oba jezika, pokazuju da su poslovice u velikom broju slučajeva značenjski ekvivalenti, što je dokaz univerzalnosti principa utelovljenja kao prepojmovnog fenomena. Ukoliko i postoje neznatne razlike, one su posledica kulturoloških i tradicionalnih uticaja.

U okviru slikovne sheme SADRŽATELJ, delovi tela konceptualizuju se poput ograničenog prostora u koji se smešta određeni sadržaj, i čije se ivice probijaju radi ispuštanja ili umetanja novog (npr. get into someone's headl ući u nečiju glavu). Dominantna prenesena značenja lekseme hand/ruka su kontrola, spas/utočište, dok se glava/head konceptualizuje kao ograničen prostor.

Slikovna shema SILA predstavlja odnos univerzuma i čoveka. Delovi ljudskog tela prikazani su u pokretu, pod uticajem sila iz univerzuma (npr. bang/bash one's head against a brick wall / razbijati glavu o nečemu), gde se pod određenim pritiskom želi nešto iznuditi, ostvariti (npr. rule with an iron hand/fist in a velvet glove / čelična pesnica). Značenje poslovica je isto u oba jezika. Dominantno preneseno značenje lekseme head/glava jeste misaoni proces/odgonetanje, dok hand/ruka označava vlast.

Slikovna shema GORE-DOLE ukazuje na istu konceptualizaciju vertikalne orijentacije $\mathrm{u}$ oba jezika. Povijena glava nadole označava tugu/sramotu, dok uzdignuta glava označava sreću/ponos (npr. keep one's head down/ gledati u zemlju; hold one's head high up/ visoko uzdignute glave).

Slikovna shema CENTAR-PERIFERIJA pokazuje da pripadnici oba posmatrana jezika imaju isto viđenje prostorne orijentacije, tj. svest o tome šta je blizu pa prema tome centralno, a šta udaljeno od centra pa prema tome periferno (npr. far from eye, far from heart / daleko od očiju, daleko i od srca). Eyes/oči preko fizičkog domena percepcije objašnjava apstraktan 24 
domen opažanja, čežnjivog pogleda, dok heart/srce predstavlja privrženost, jake emocije prema nekoj osobi. Unutar ove sheme, hand/ruka se konceptualizuje kao sadržatelj (npr. a bird in the hand is worth two in the bush/ bolje vrabac u ruci nego golub na grani).

Prema kulturnom modelu oba posmatrana jezika, glava je centar racionalnog razmišljanja što čoveka razlikuje od životinja. Svako pomeranje glave dovodi do narušavanja uspostavljene ravnoteže. U okviru slikovne sheme RAVNOTEŽA, uočavamo da pomeranje glave pod uticajem emocija dovodi do prevlasti emocionalnog mišljenja nad racionalnim (npr. make somebody's head spin / zavrteti nekome glavu), što za posledicu ima ponašanje nesvojstveno pojedincu. Mirna nepokretna glava u prenesenom značenju predstavlja stabilnost, racionalno razmišljanje, dok glava koja se vrti predstavlja nestabilnost, gubitak racionalnog razmišljanja.

Slikovna shema PREDMET konceptualizuje delove ljudskog tela poput predmeta kojima se manipuliše. Oni mogu biti dragoceni, te se njihovim gubitkom gubi život (npr. place one's head in the lion's mouth I staviti glavu na kocku) i sl. Dominantno preneseno značenje lekseme head/glava je dragocen predmet.

Zaključujemo da su poslovice značenjski ekvivalenti jer govornici dva jezika pribegavaju istim kognitivnim mehanizmima. Dominantno preneseno značenje lekseme head/glava je sadržatelj za racionalne misli, s tim da ponekad označava i dragocen predmet. Položaj glave nam ukazuje na osećanja poput sreće i ponosa kada je glava uzdignuta, i tuge i stida kada je glava pognuta. Hand/ruka najčešće označava sadržavanje, kontrolu, spas/utočište. Heart/srce označava centar emocija što je suprotno od glave koja označava centar racionalnog razmišljanja. Eyes/oči ukazuju na čežnjivi pogled/strepnju, što je više emocionalno obojeno posmatranje u odnosu na osnovno značenje čula vida. Ostali delovi tela poput belly/stomak, ears/uši, finger/prst, foot/stopalo i tongue/jezik u korpusu beleže po jedan primer koji zbog ekonomičnosti prostora nije mogao biti prikazan u ovoj analizi. Dominantno preneseno značenje lekseme belly/stomak je gladna osoba, ears/uši je moć opažanja/razumevanje za određenu situaciju. Finger/prst predstavlja nečije neželjeno prisustvo, foot/stopalo označava fizički pad, dok tongue/jezik, s druge strane, predstavlja moralni pad. 


\section{ZAKLJUČAK}

Apstraktne koncepte motivišu naša fizička iskustva (Lakoff \& Johnson 1980) i kulturno poreklo koje nas okružuje (Kövecses 2005). Pojmovna metafora predstavlja mehanizam posredstvom kog čovek opaža stvarnost, situacije i iskustva. Tačnije, čovek putem sopstvenog tela percipira spoljašnji svet pripisujući pojavama i situacijama svojstva tipična za pojedine delove svog tela. Ta svojstva se prvenstveno odnose na oblik, položaj ili funkciju koju određeni delovi tela obavljaju. Imajući u vidu činjenicu da primenom pojmovne metafore apstraktne pojmove objašnjavamo putem konkretnih, opipljivih pojmova, zaključujemo da naše telo, budući da je vidljivo, opipljivo, i za kojim nesvesno posežemo u razumevanju istih, predstavlja idealan poredbeni obrazac koji nam olakšava razumevanje apstraktnih pojava.

U radu su upoređivana značenja poslovica $u$ okviru kojih se nalaze somatizmi. Posebna pažnja posvećena je prisustvu pojmovnih metafora $u$ oba jezika, njihovim istostima, sličnostima i razlikama kroz prisustvo slikovnih shema SADRŽATELJ, SILA, RAVNOTEŽA, CENTAR-PERIFERIJA, GORE-DOLE, i PREDMET u oba jezika. Rezultati istraživanja ukazuju na brojna konceptualna poklapanja između dva suprotstavljena jezika, engleskog i srpskog, koji su po svom poreklu, geografski i kulturološki udaljeni. Ova činjenica svedoči o tome da je mišljenje univerzalno i ne zavisi od socijalnih i kulturoloških faktora, kao i to da konceptualizujemo stvarnost na osnovu utelovljenja koje je svojstveno svima, bez obzira na to gde živimo i odakle dolazimo.

Analizom je takođe ustanovljeno da su kognitivni mehanizmi i pojmovni obrasci koji motivišu značenje poslovica u velikoj meri slični u oba jezika. To svakako doprinosi lakšem razumevanju i usvajanju poslovica govornicima engleskog i srpskog jezika jer često imaju iste mentalne predstave i na sličan način interpretiraju apstraktne pojmove. Bez obzira na kulturu kojoj pripadaju, i jedni i drugi imaju istu svest i znanje o ljudskom telu koje je nezavisno od bilo kakvih konvencionalnosti. Neophodno je navesti da bi svako buduće istraživanje na većem korpusu, svakako doprinelo detaljnijoj analizi i dodatnim kulturološkim i pojmovnim nijansama u konceptualizaciji delova tela na engleskom i srpskom jeziku. 


\section{LITERATURA}

Barcelona, Antonio. 1997. "The State of the Art in the Cognitive Theory of Metaphor and Metonymy and its Application to English Studies." Atlantis XIX/1: 21-48.

Barcelona, Antonio. 2002. "Guidelines for the application of the theories of metaphor and metonymy to textual examples". Theoria et Historia Scientiarum, Vol. VI, $\mathrm{N}^{\circ} 1$ Ed. Nicolas Copernicus University.

Cvetanović, Katarina. 2017. Metaforički i metonimijski obrasci u srpskim $i$ engleskim idiomima sa nazivima delova tela. Novi Sad: Filozofski fakultet (diplomski rad pod mentorstvom doc. dr Ane Halas Popović).

Deignan, Alice. 2005. "A Corpus Linguistic Perspective on the relationship between Metonymy and Metaphor." Style 39(1): pp. 72-91.

Živadinović, Jovana. 2016. Pojmovna metafora u idiomima sa nazivima delova tela $u$ engleskom i srpskom jeziku. Novi Sad: Filozofski fakultet (diplomski rad pod menstorstvom prof. dr Sabine Halupke Rešetar).

Hampe, Beate. ed. in cooperation with Joseph E. Grady. 2005. From perception to meaning: image schemas in cognitive linguistics. Berlin: Mouton de Gruyter.

Johnson, Mark. 1987. The Body in the Mind. The Bodily Basis of Meaning, Imagination, and Reason. Chicago: Chicago University Press.

Johnson, Mark. 2005. "The philosophical significance of image schemas." In: Hampe, B. (ed.), From perception to meaning: Image schemas in cognitive linguistics. Mouton de Gruyter, Berlin/New York: 1533. 11

Klikovac, Duška. 2004. Metafore u mišljenju i jeziku. Beograd: Biblioteka XX vek.

Kövecses, Zoltán. 2002. Metaphor. A Practical Introduction. Oxford: Oxford University Press.

Kövecses, Zoltán. 2005. Metaphor in Culture: Universality and Variation. Cambridge, New York: Cambridge University Press.

Lakoff, George. \& Johnson, Mark. 1980. Mefaphors we live by. Chicago and London: University of Chicago Press.

Lakoff, George. \& Turner, Mike. 1989. More than Cool Reason. Chicago: The University of Chicago Press. 
Niemeier, Susanne. 2008. "To be in control: kind-hearted and cool-headed. The head-heart dichotomy in English." In: Sharifian, F., R. Dirven, $\mathrm{N}$. $\mathrm{Yu}$ and $\mathrm{S}$. Niemeier (eds.), Culture, Body, and Language: Conceptualizations of Internal Body Organs across Cultures and Languages, Mouton de Gruyter, Berlin: 349-372.

Prćić, Tvrtko. 2008. Semantika i pragmatika reči. 2., dopunjeno izdanje. Novi Sad: Zmaj.

Prodanović-Stankić, Diana. 2008. Životinje u poslovicama na engleskom $i$ srpskom jeziku. Beograd: Zadužbina Andrejević.

Prodanović-Stankić, Diana. 2009. "Pojmovna metonimija i metafora u značenjima lekseme srce u srpskom jeziku". Godišnjak Filozofskog fakulteta, Novi Sad, 34, 1, 77-87.

Radić-Bojanić, Biljana. \& Silaški, Nadežda. 2012a. "Head as a Container in English and Serbian - A Cognitive Linguistic Perspective“. The Journal for Languages and Literatures of the Faculty of Philosophy in Novi Sad. Volume II, pp. 65-78.

Radić-Bojanić, Biljana. \& Silaški, Nadežda. 2012b. "Metaphoric and Metonymic Conceptualizations of the Head - A Dictionary-Based Contrastive Analysis of English and Serbian". Linguistics and Literature Vol. 10, No 1, pp. 29-39.

Silaški, Nadežda, \& Radić-Bojanić, Biljana. 2014. "Metonymy in expressions pertaining to hand / ruka in English and Serbian". In: Z. Đergović-Joksimović \& S. HalupkaRešetar (eds.) English Studies Today: Prospects and Perspectives (pp. 29-37). Novi Sad: Faculty of Philosophy, University of Novi Sad.

Skok, Petar. 1971. Etimologijski rječnik hrvatskoga ili srpskoga jezika. Zagreb: Jugoslavenska akademija znanosti i umjetnosti.

Szwedek, Aleksander. 2000. "The ontology of metaphors: the sense of touch in language formation." Scripta Periodica 4, 193-200.

Szwedek, Aleksander. 2002. "Objectification: From Object Perception To Metaphor Creation." Cognitive Linguistics To-day. Eds. B. Lewandowska-Tomaszczyk and K. Turewicz. Frankfurt am Main: Peter Lang. 159-175.

Szwedek, Aleksander. 2009. "Conceptualization of space and time." Language, Science and Culture. Eds. P. Łobacz, P. Nowak, and W. Zabrocki. Poznań: Wydawnictwo Naukowe UAM. 317-333. 
Szwedek, Aleksander. 2011. "The ultimate source domain." Review of Cognitive Linguistics 9: 2, 341-366.

Szwedek, Aleksander. 2014. "The nature of domains and the relationships between them in metaphorization." Review of Cognitive Linguistics 12: $2,342-374$.

Yu, Ning. 2009. From Body to Meaning in Culture. Amsterdam/Philadelphia: John Benjamins Publishing Company.

Szwedek, Aleksander. 2017. "The Object Schema". URL:https://www.researchgate.net/publication/312371970_The_O

BJECT_image_schema (29.12.2018)

George Lakoff, George. 1994. Master Metaphor List (MML). University of California, Berkeley. URL:http://www.lang.osakau.ac.jp/ sugimoto/MasterMetaphorList/metaphors (28.8.2018)

Rečnici:

Collins COBUILD Dictionary of Idioms (1995)

Dictionary of Selected Collocations (1997)

Englesko-srpski rečnik fraza i idioma (1995)

Longman Collocation Dictionary and Thesaurus (2013)

Longman Dictionary of English Idioms (1990)

Macmillan Collocations Dictionary (2010)

Oxford English Idioms (1988)

Srpsko-engleski rečnik idioma (1991)

Srpsko-engleski rečnik idioma, izraza i izreka (1992)

The BBI Dictionary of English Word Combination (1997)

The Penguin Dictionary of English Idioms (1986)

The Idiom Connection: English Idioms and Quizzes. URL: http://www.idiomconnection.com

The Free Dictionary: Idioms and Phrases. URL: http://idioms.thefreedictionary.com 
Slađana Mandić

\section{IMAGE SCHEMAS IN ENGLISH AND SERBIAN PROVERBS CONTAINING SOMATISMS: FROM COGNITIVE LINGUISTIC PERSPECTIVE}

\section{Summary}

This paper has dealt with the analysis of image schemas CONTAINER, FORCE, BALANCE, CENTER-PERIPHERY, UP-DOWN, and OBJECT (Johnson 1987) in English and Serbian proverbs containing somatisms like Place one's head in the lion's mouth in English, and Staviti glavu na kocku in Serbian. The research is based on the corpus of 30 English and Serbian proverbs equally. The main aim of the research is to define dominant metaphoric patterns which motivate the usage of body parts in proverbs, as well as to present image schemas through the embodiment principle which explains how abstract concepts are motivated by our physical experiences (Lakoff \& Johnson 1980). Moreover, we understand the world through the shapes and movements of our own body parts. The results of the analysis show there is a high degree of correspondence between the two contrasted languages, English and Serbian, in respect of the ways the speakers of both languages conceptualize the world around them by using alike image schemas and conceptual metaphors based on the interaction of human body and the environment.

Key words: proverbs, somatisms, cognitive linguistics, image schemas, English language, Serbian language. 
DODATAK: SPISAK POSLOVICA NA ENGLESKOM I SRPSKOM JEZIKU

\begin{tabular}{|c|c|c|}
\hline & Engleskijezik & Srpskijezik \\
\hline & HEAD & GLAVA \\
\hline 1. & Get into someone's head & Ući u nečiju glavu \\
\hline 2. & To drum/put/beat sth into sb's head & Puniti nekome glavu \\
\hline 3. & To knock sth out of sb's head & Izbiti nekome nešto iz glave \\
\hline 4. & Keep one's head down & Gledati и zemlju \\
\hline 5. & $\begin{array}{l}\text { Hold one's head high/up/in the } \\
\text { clouds }\end{array}$ & Visoko uzdignute glave; sanjariti \\
\hline 6. & Bury one's head in the sand & Zabiti glavu u pesak \\
\hline 7. & Keep one's head above water & Sastavljati kraj s krajem \\
\hline 8. & To be head over ears in debt & Biti u dugovima do guše \\
\hline 9. & A fish begins to stink at its head & Od glave riba smrdi \\
\hline 10. & $\begin{array}{l}\text { To be/fall head over heels/ears in } \\
\text { love }\end{array}$ & Izgubiti glavu; zaljubiti se do ušiju \\
\hline 11. & Make somebody's head spin & Zavrteti nekome glavu \\
\hline 12. & $\begin{array}{l}\text { Bang/bash one's head against a } \\
\text { brick wall }\end{array}$ & Razbijati glavu o пес̌ети \\
\hline 13. & Not harm a hair of sb's head & Neće ti faliti ni dlaka s glave \\
\hline 14. & $\begin{array}{l}\text { Place one's head in the lion's } \\
\text { mouth }\end{array}$ & Staviti glavu na kocku \\
\hline \multirow[t]{2}{*}{15.} & To lose one's head & Izgubiti glavu \\
\hline & HAND & RUKA \\
\hline 16. & $\begin{array}{l}\text { Have somebody in the palm of } \\
\text { one`s hand }\end{array}$ & Imati nekog u šaci \\
\hline 17. & Take one's life in one's hands & Uzeti život u svoje ruke \\
\hline 18. & Be in good hands & Biti u dobrim rukama \\
\hline 19. & $\begin{array}{l}\text { Have somebody eating out of one's } \\
\text { hand }\end{array}$ & Jesti nekome iz ruke \\
\hline
\end{tabular}




\begin{tabular}{|c|c|c|}
\hline 20. & $\begin{array}{l}\text { A bird in the hand is worth two in } \\
\text { the bush }\end{array}$ & $\begin{array}{l}\text { Bolje vrabac u ruci nego golub na } \\
\text { grani }\end{array}$ \\
\hline 21. & $\begin{array}{l}\text { Rule with an iron hand/fist in a } \\
\text { velvet glove }\end{array}$ & Čelična pesnica \\
\hline 22. & Take the law into one's hands & Uzeti zakon u svoje ruke \\
\hline 23. & Bite the hand that feeds one & Hrani pseto da te ujede \\
\hline \multirow[t]{2}{*}{24.} & Give/lend a (helping) hand & Ići nekome na ruku/pružiti ruku \\
\hline & $\begin{array}{l}\text { BELLY, EYES, EARS, HEART, } \\
\text { FINGER, FOOT, TONGUE }\end{array}$ & $\begin{array}{c}\text { STOMAK, OČI, UŠI, SRCE, PRST, } \\
\text { STOPALO, JEZIK }\end{array}$ \\
\hline 25. & Far from eye, far from heart & Daleko od očiju, daleko i od srca \\
\hline 26. & A hungry belly has no ears & Gladnog ne teši već nahrani \\
\hline 27. & Better the foot slip than the tongue & $\begin{array}{l}\text { Bolje je pokliznuti nogom nego } \\
\text { jezikom }\end{array}$ \\
\hline 28. & Hawks will not pick hawks' eyes & Vrana vrani oči ne vadi \\
\hline 29. & To have a finger in every pie & $\begin{array}{l}\text { Biti u svakoj čorbi mirođija; Gurati } \\
\text { nos u sve i svašta }\end{array}$ \\
\hline
\end{tabular}

